\title{
Non-Metastatic Childhood Rhabdomyosarcoma
}

National Cancer Institute

\section{Source}

National Cancer Institute. Non-Metastatic Childhood Rhabdomyosarcoma. NCI

Thesaurus. Code C8065.

Rhabdomyosarcoma that occurs during childhood and is confined to the site in which it initially manifested. 